\title{
APORIAS DA PERFORMANCE NA EDUCAÇÃO
}

\author{
ELAINE CONTE \\ Universidade Federal do Rio Grande do Sul
}

\section{CONSIDERAÇÕES INICIAIS}

Os problemas pedagógicos poderiam ser repensados por uma melhor compreensão da linguagem que usamos presentemente como instrumento natural, como a voz do sujeito para lidar com o mundo, pois a expressividade é algo intrínseco à linguagem humana. No entanto, a racionalidade que impera no cotidiano é aquela voltada para a instrumentalização da vida, uma concepção objetivadora (de ação por coerção) engessada em conceitos que reprimem a expressividade humana. Daí a necessidade de orientarmos a discussão com base em perspectivas procedentes da teoria da comunicação (que permite a reconstrução da materialidade perdida da experiência estética), para utilizarmos um conceito de razão performativa corporificada no agir orientado para o entendimento.

Seguindo de perto as pegadas de Jürgen Habermas referentes à dimensão estética na arquitetônica da racionalidade comunicativa, partilhamos da necessidade dos meios da pragmática da linguagem agirem sobre os complexos de saber modernos que se diferenciaram sob o aspecto da validade, da verdade, da correção normativa e da autenticidade. Contra uma redução empirista da problemática da racionalidade, Habermas defende a comunicabilidade das diferentes justificativas das pretensões de validade dos juízos teóricos, morais e estéticos. Destaca ainda que a legitimidade de uma racionalidade prático-estética é formada pela validade que atribuímos ao seu poder de abrir nossos olhos à complexidade da experiência vital, como um jogo entre a autenticidade da expressão e a adequação normativa.

Por essa razão, Habermas (1987, p. 369, tradução minha) parte, em sua pragmática dos atos de fala, das teorias inauguradas por Wittgenstein (na segunda 
fase de suas produções), por Austin, por Searle e demonstra, assim, que "os conceitos de fala e entendimento se interpretam um ao outro", originariamente e de forma evidente. O momento criativo da constituição linguística do mundo forma os momentos cognitivo-instrumentais (razões científicas voltadas ao êxito), prático-morais (razões normativas ou sábias) e estético-expressivos (razões sinceras e autocríticas), bem como as funções intramundanas da linguagem (de exposição, de relação interpessoal e de expressão subjetiva). Jürgen Habermas fala da performance na perspectiva do uso comunicativo da linguagem que agrega todos os produtos da cultura, da arte, da vida cotidiana, da literatura, do cinema, como elementos linguísticos para encontrarmos respostas às perplexidades do mundo.

Para Wittgenstein, ${ }^{1}$ não importa o que está por trás das aparências e dos processos mentais, importa o que está manifesto, o que pode ser analisado nos diferentes jogos de linguagem, isto é, nos diferentes usos de expressões linguísticas. "Como esclareceu Wittgenstein, o telos do entendimento mútuo é inerente ao próprio medium linguístico" (Habermas, 2009, p. 108), dado o seu caráter intersubjetivo e formador de mundo, tal qual a linguagem exigida dos participantes de um discurso performativo. De fato, o horizonte da linguagem como ação viva no mundo, que articula logos (palavra) e práxis (ação) na dialética estético-expressiva, remete à questão da performance. Conceitualmente, o termo performance é complexo e polêmico, não apenas porque abriga uma multiplicidade de formas e o colapso dos limites entre vida e arte, mas também porque tem estado em permanente transformação desde o seu surgimento.

Trata-se, aqui, de olhar para as necessidades artísticas e filosóficas da formação pedagógica não como instrução ou mera reprodução de conhecimento, mas como a formação de sujeitos criadores de performances próprias. No processo educativo, o conhecimento tem sua única expressão na linguagem (instância intranscendível da expressividade humana), e não em fórmulas e verdades dogmáticas. A superação da ingenuidade do fazer pedagógico assentado em técnicas e certezas implica, hoje, na tematização não só da mediação pela consciência, mas também da mediação

1 Ao segundo Wittgenstein estão associadas as obras posteriores ao Tratactus logico- philosophicus. Para isso, veja-se: Ludwig. Wittgenstein, Investigaçóes filosóficas, tradução de José Carlos Bruni, São Paulo, Abril Cultural, 1979 (Os pensadores).

2 A raiz do conceito performance deriva do verbo inglês to perform, termo correlato do substantivo ação. Para Austin, um ato de fala performativo é um agir humano de voz ativa e realizadora, com força ilocucionária, pois tem o propósito de chegar a um acordo interpessoal que sirva de base à coordenação dos planos de ação individuais. A formulação que inquieta e move este estudo se encontra em Habermas, que remete às diversas formas de desempenho discursivo, na medida em que a performance está ligada à ação do homem no mundo. Trata-se de uma ação que não pode ser reduzida às operações interpretativas dos participantes na interação, como nos alerta Habermas (1987, p. 138, tradução minha), "em que atuar se assemelhe a falar e interação, à conversação". Performance desencadeia um gesto expressivo, presente na linguagem, que expande a própria comunicação, visto que integra as relações entre linguagem e mundo nas redes de socialização comunicativa. 
linguística como forma de tornar-se crítico e habitar o mundo expressivamente, justificando, assim, a sua racionalidade no mundo prático e intersubjetivo.

De nosso ponto de vista, buscamos recolocar em exame a emergência dos novos temas em articulação com o conjunto das problemáticas educacionais do nosso tempo; e com uma delas em particular, a performance. A ação performativa diz respeito ao cerne da prática educativa, ao ato de comunicar, de mobilizar nos outros sujeitos novas construções de saber, como também de tornar presente a produção de novos sentidos (sensíveis e inteligíveis) para a formação docente. A linguagem é um aspecto primordial do sentido da performance do professor, na medida em que opera os argumentos com o auxílio do corpo, no sentido da presença de pontos de vista. Contudo, declarações performativas têm, ao mesmo tempo, um sentido linguístico e um sentido institucional, uma vez que possibilitam o situar-se de expressões linguísticas, isto é, estabelecem seu próprio sentido pragmático de emprego da ação.

Nesse contexto, é inevitável que nossos argumentos venham como pontos de interrogação: por que a dimensão linguístico-expressiva (performativa) ficou restrita, nos processos de formação de professores, à hora de improvisar, no instante da apresentação de um trabalho? Como é compreendida e qual o papel da performance (atuação sensível) na dimensão formativa do professor? Que formação daria conta de um profissional performativo? Em todo caso, a reflexão pode se autorizar a abrir mão do purismo interno dos diferentes discursos para acolher as lições do multiculturalismo e da diferença, de modo que reveja nossa interpretação da performance, em nome da mais autêntica tradição da educação que, desde os gregos, se entende como diálogo. Nesse cenário, é mobilizando o saber performativo que a pedagogia estará em condições de retomar a problemática do sujeito e realizar a intersubjetividade comunicativa.

\section{HORIZONTES DA PERFORMANCE}

Os contornos do que hoje podemos chamar de performance remontam aos antigos gregos cuja tradição concorda que a representação de um texto dramático é uma performance, uma prática compartilhada e relacionada com o mundo. $\mathrm{Na}$ Antiguidade, Aristóteles (384-322) abdicou a separação platônica entre imagens dos mundos inteligível e sensível, propondo em seu lugar a teoria do ato e da potência, uma ideia de movimento a algo que pode ser potencializado no próprio ente em estado atual. A performance na teoria aristotélica refere-se à práxis, está relacionada com o caráter e direcionada pela racionalidade, pois é do desempenho excelente que se chega à virtude. Com seu tratado sobre a Poética (Poétique, 1995), observa que a arte pertence à esfera da atividade prática, tendo sua origem na imitação e na intuição. Desde Aristóteles, a ação performativa (de gênero dramático) é entendida como aquele agir em que o ator imita as ações humanas e as atualiza, por meio da expressão imediata da corporeidade do ator social em cada cena. A imitação atualizada em tempo presente não reproduz simplesmente caracteres dos personagens, 
mas mostra-os agindo. Nesse sentido, o estético-expressivo era o caminho segundo o qual algumas práticas eram problematizadas como phronèsis. ${ }^{3}$

Já no tratado sobre a Retórica (Rhétorique, 1932), Aristóteles apresenta um conhecimento da arte de persuadir, dizendo que tem por objetivo encontrar um conhecimento persuasivo e confiável acerca das técnicas ${ }^{4}$ dos limites da ação humana em cada situação. Sendo a retórica uma forma de orientação ao trabalho do orador/ professor na busca pelo discurso desejado/aceito pelo público e, ao mesmo tempo, uma possibilidade de revisão do discurso. Ainda de acordo com o filósofo, a forma mais completa das belas-artes é a tragédia, porque produz a purificação ou catarse de circunstâncias sociais que precisam ser conhecidas. Por tal forma poética de discurso, nossos sentidos tornam-se movidos por outra dramaturgia, outra literatura ou outras formas de expressão, mas, para isso, precisamos nos envolver de alguma maneira nos modos de vida e cultura dos grupos humanos que as produzem para apreendermos seu significado.

Considera-se que a educação é, necessariamente, negociação dos significados compartilhados pela cultura em seus diversos exemplos de realização discursiva. Esse tipo de autorreflexão é hoje conceitualizada de forma mais convincente pela filosofia hermenêutica. ${ }^{5}$ Pode-se inferir daí que a performance abre possibilidades interpretativas, porque se insere na mobilidade da linguagem, irradiando múltiplas significações para a realização do que se expressa; na lógica de que é performando papéis que nos constituímos num perpétuo e necessário desequilíbrio, pois estamos sempre atuando e exercitando uma autocrítica mesmo que ela não seja evidente.

A performance tinha um forte conteúdo das artes, mas, ao longo das duas últimas décadas, pode-se afirmar que a performance está mais orientada pela narrativa,

3 Para Aristóteles, a ação é necessariamente ética, sendo que a phronèsis (a prudência ou a sabedoria prática que dirige a ação) lhe dá essa dimensão ética de agir bem. A verdadeira prudência consiste em achar a justa medida (meio-termo) e em arriscar-se à ação criadora e, no mesmo ato, dominá-la. É uma performance ideal que Aristóteles defende, cujo discurso decorre da estrutura intuitiva de uma emissão, constitutiva de três elementos: aquele que fala (falante), o sujeito sobre o qual ele fala e aquele a quem ele fala (o auditor, ao qual se dirige o fim).

4 Qualquer técnica de discurso é um ajuste permanente entre o idealizado e o que se faz ou pode ser feito, porque uma técnica não pode ser precisa, rigorosa, por ser condicionada, contingente e imprevisível.

5 A compreensão hermenêutica de Gadamer (2002) visava a uma verdade que se manifestava na arte, na história e na linguagem, acompanhando as discussões de sentido e significado postas pelas ciências humanas. Gadamer é o primeiro a acentuar a abertura ao diálogo como algo vivo, de experiência presente, no sentido de afirmar que é uma ilusão pensar que seja possível ter a última palavra. Fazendo uma analogia com a educação, também não é possível uma pedagogia segura de seus fundamentos, segura da ação a ser realizada, do gesto ou olhar a ser feito, das palavras a serem ditas, porque está enraizada no devir das realidades inapreensíveis, na ação e na sensibilidade para o acontecimento performativo. Gadamer diz que não haveria orador nem arte da fala se as relações humanas não fossem sustentadas pela compreensão de um diálogo perturbado e pelo acordo (que devesse ser procurado). 
sendo que um dos seus traços principais é o seu caráter autoral, de ação comunicativa evidente. O filósofo Austin (1911-1960) situa a linguagem humana no seio do processo comunicativo e defende que a linguagem é uma ação humana. Por essa razão é que Austin (1990) observa que a elocução performativa dita por um ator no palco é vazia, uma vez que ele representa um personagem. Em contrapartida, o professor é o autor do seu próprio script, pois não pretende representar um outro sujeito distanciado de sua linguagem e gestos, ou habitar um espaço e tempo fictícios, mas apresenta uma atualidade e um forte caráter público de interação com o mundo (de um sujeito que se abre para e se identifica com múltiplas vozes); tendo em vista que não somos apenas seres pensantes,

somos também seres que agem no mundo, que se relacionam com os outros seres humanos, com os animais, as plantas, as coisas, os fatos e acontecimentos, e exprimimos essas relações tanto por meio da linguagem quanto por meio de gestos e ações. (Chauí, 1999, p. 14)

Embora a formação docente negligencie o espaço à sensibilidade humana ao aprendizado por conta própria, Freire (2002, p. 70) observa que o agir docente como um "que fazer" de insensíveis fica circunscrito a um racionalismo que esvazia o trabalho educativo de vida e de sentimentos. Muitas vezes, a impressão subjacente é de que a competência discursiva, científica e política dos professores surge por uma aplicação monológica de ações particulares ou por decreto. De qualquer forma, seria muito idealismo da nossa parte querer qualificar a educação sem uma contrapartida em termos de condições dignas (piso salarial como padrão valorativo de nosso tempo) para o trabalho. Assim como é contraditório pensar a performance do professor como realização humana (estímulo ao agir correto eticamente, felicidade na ação) no isolamento dos sujeitos ou na alienação do mundo da vida. O debate sobre a performance trata de responder aos desafios de nossa época e retomar a ação dialógica no predomínio da razão instrumental.

\section{RACIONALIZAÇÃO DA COMUNICAÇÃO E TRANSMISSÃO DO CONHECIMENTO}

Para Habermas (1990b), teria ocorrido uma racionalização da comunicação cotidiana e uma racionalização do mundo sistêmico, causando a fragmentação absoluta de todos os domínios das atividades humanas, sobretudo das práticas pedagógicas justificadas na pedagogização (ação técnica que visa convencer), ori-

6 O processo de racionalização dá-se pela ampliação do saber empírico, da capacidade de predição, bem como do domínio instrumental e organizativo sobre os processos empíricos. Para Habermas (1987, p. 202, tradução minha), "o progresso científico pode converter-se em racionalização da vida social se os cientistas assumem a tarefa da educação pública com a finalidade de converter os princípios de seu próprio trabalho em princípios de comércio e trato sociais". 
ginando um sujeito deficitário. Há também a perda de uma razão integradora do saber gerando o mundo das especializações e da produção cultural contemporânea.

Segundo Habermas, essa pedagogização dos processos de educação formal atinge hoje o âmbito da socialização, tal como os sistemas culturais de ação e a formação da vontade política. Sobre esse raciocínio, Habermas (1999, p. 208, tradução minha) argumenta que "a formalização da educação significa não somente um tratamento profissional, mas também uma refração reflexiva da reprodução simbólica do mundo da vida”. Desse modo, nas práticas habitualizadas, os processos de aprendizagem passam a ser regidos pela lógica da competição e da racionalidade instrumental, que sistematiza as relações entre saber, produtividade e desempenho.

Essa ideia de uma transformação objetiva na sociedade tem relação também com a invasão da ciência no mundo do trabalho, cujo processo modifica o mundo e a própria natureza do ser humano. Assim, falar de linguagem remete à práxis que gesta a sociabilidade, pois a interna conexão de ambas pode logicamente se mostrar como uma atividade intersubjetiva que parte do conhecimento de vida. A tradição materialista permitiu compreender que o trabalho humano tem um caráter contraditório por constituir-se em fonte de humanização e, ao mesmo tempo, pura dominação capitalista pelas condições objetivas nas quais a ação e o saber humano podem realizar-se. Como já sugeria o jovem Marx (1978, p. 9):

É somente graças à riqueza objetivamente desenvolvida da essência humana que a riqueza da sensibilidade humana subjetiva é em parte cultivada, é em parte criada, que o ouvido torna-se musical, que o olho percebe a beleza da forma, em resumo, que os sentidos tornam-se capazes de gozo humano, tornam-se sentidos que se confirmam como forças essenciais humanas.

As indicações de Marx revelam as eternas necessidades da vida humana contingente, em termos de processos de trabalho, que apresentam momentos estéticos constitutivos de nosso saber e de nossa construção da realidade. É nesse sentido que Marx critica o antigo materialismo (até Feuerbach) por não captar a dimensão ativa do trabalho como forma de expressão humana. Ora, se a dimensão estética tem possibilidades de evidenciar limitações da realidade social, é justamente por intermédio da crítica ao mecanismo da automatização que condiciona a expressividade e formata nossa compreensão do mundo. Embora a citação toque na importância da sensibilidade, Habermas (1990b) adverte que a proposta materialista de conhecimento é redutora, na medida em que elege a categoria trabalho, identificando-a com a consciência e estabelecendo que apenas nas relações de trabalho podem ser realizados os potenciais da racionalidade contidos na sociedade. Dessa forma, com a práxis ocorreu a subsunção da racionalidade comunicativa à razão instrumental isenta de solidariedade.

É exatamente a ausência de sensibilidade que parece caracterizar a evolução atual das instituições de formação de professores, que caminham em direção à extinção de espaços linguísticos, filosóficos, sociológicos, da estética e da ética, entre outras áreas, dando ênfase à dimensão técnico-instrumental integrada à economia. 
De acordo com Habermas (1996, p. 285, tradução minha), "a linguagem natural de que se faz uso na educação parece que somente se desenvolve de forma auxiliar com fins didáticos, tomando instrumentalmente a linguagem a seu serviço". Isso nos leva a acreditar que, quando nossa capacidade de conversar e, portanto, de elaborar conceitos é limitada em vários aspectos, tendemos a fazer da educação um treinamento de visões dogmáticas em que a repetição de procedimentos padronizados passa a ser sinônimo de aprendizagem autêntica.

Todavia, por meio desse tipo de formação se exclui a priori qualquer autorreflexividade e respeito pela alteridade. Assim, apontamos a necessidade de uma transformação da base do saber ${ }^{7}$ expresso nos controles de ação para a ideia de desempenho (Einlösung) ${ }^{8}$ discursivo de pretensões de validade (a verdade das proposições, a retidão das normas morais, a veracidade expressiva e inteligibilidade), racionalmente criticáveis.

Embora uma estética discursiva não seja pensada como uma estética normativa, essa problemática recai sobre as condições normativas que constituem a forma do procedimento próprio à argumentação estética. $\mathrm{O}$ seu objeto de análise não é a obra de arte, e sim o devir comunicativo da experiência estética, ou seja, o modo pelo qual justificamos os critérios que orientam nossos juízos e o validamos na prática intersubjetiva da argumentação.

Cabe fazer a distinção entre o discurso esclarecido do conceito de performance e a institucionalização política desse discurso. Vale lembrar que o termo performance, que ressoa no campo da educação, é proveniente de uma tradição positivista, compreendida como domínio de procedimentos e técnicas, que busca sua legitimação no melhor desempenho funcional e sistêmico dos professores. Por essa razão, as políticas educacionais e a organização curricular utilizam esse conceito para fins de acordos descritivos, que têm como pressuposto a ação intervencionista de medir a eficiência do ensino, perdendo de vista o seu caráter linguístico estruturado.

O tratamento superficial com relação à linguagem na educação tende a produzir reducionismos conceituais e confundir expressividade subjetiva com adesão acrítica a modelos retóricos. Ora, não é de estranhar que um pensamento que abandona a possibilidade de produção intersubjetiva do saber venha a cair num sistema de interpretações simplistas que impedem processos de aprendizagem argumentativos, pois utilizam percepções de desempenho operacional ou experiências antiquadas, alheias a um saber mais responsável. A compreensão da construção de

7 A expressão saber é tudo aquilo que pode ser adquirido por aprendizagem e por apropriação da tradição cultural, estendendo-se tanto aos elementos cognitivos da cultura quanto aos elementos expressivos e prático-morais concernentes à integração social, revelando que nossas identidades são formadas culturalmente (Habermas, 1999, p. 256).

8 "Einlösung (desempenho, verificação) significa que o falante, apelando para experiências e intuições ou por argumentação e consequências da ação, justifica que o dito é digno de ser reconhecido e dá lugar a um reconhecimento intersubjetivo de sua validez" (Habermas, 1987, p. 26, tradução minha). 
competências na política oficial ${ }^{9}$ é situada em um horizonte técnico que procura sua legitimidade na otimização do fazer dos professores e no melhor desempenho funcional das instituições formadoras.

Nesse contexto, as políticas educacionais, assim como os produtos culturais, funcionam como uma espécie de redirecionamento da percepção, que tudo submetem a uma homogeneização, para a manutenção do que interessa ao capital. O pressuposto disso é que desapareça o sujeito capaz de perceber por si mesmo, na autenticidade do devir comunicativo da competência estética, imperando uma espécie de respeito exacerbado pelas convenções, que cede espaço a um livre desenvolvimento da indústria cultural. De modo conhecido, essa discussão aponta para a baixíssima qualidade dos produtos didáticos distribuídos em massa pela indústria cultural, os quais embotam os sentidos, fazendo com que a sensibilidade criativa perca progressivamente o seu poder, redundando numa deseducação estética que promove a "semiformação" ${ }^{10}$ Nesse caso, surge a necessidade de criticar a mercantilização do diálogo e também o sentido dessas normas e convenções discursivas como forma de reeducar os sentidos humanos como práxis social, não como mercadoria.

A perspectiva de Gadamer (1983) auxilia-nos na medida em que mostra a incapacidade para o diálogo como uma tendência generalizada de toda a sociedade no mundo contemporâneo. Parece que quanto mais o ser humano domina os instrumentos tecnológicos e é invadido por eles, mais incapazes os indivíduos se tornam para o diálogo e a autocrítica no trabalho com as diferenças. Essa tendência utilitarista e unidimensional do saber, análoga aos juízos estéticos, promove nos professores uma atitude de conformidade normativa, resultando numa postura solipsista e transmissora, que substitui a orientação para o entendimento por mecanismos de comunicação associados à pretensão de poder.

A análise de Habermas (1990a) revela que a guinada linguística, por ter ocorrido inicialmente no interior do semanticismo, teve como consequência o processo de abstração que acabou recortando a linguagem de seu caráter autorreferencial, tornando impossível reaver a amplitude do sujeito radicalizado na linguagem. $\mathrm{O}$ importante, explica Habermas (idem,p. 55), é ir além da essencialidade das formas de

9 Atualmente, a noção de competência tem permeado as várias iniciativas políticas da área educacional propostas pelo Ministério da Educação (MEC). O paradigma das competências como referência principal para a (re)organização técnica dos cursos de formação de professores vem reforçando tendências procedimentais da ação pedagógica, sustentado por uma ideologia que contribui para a busca de praticidade e produtividade, produzindo mais conformação e burocratização que a melhoria do sistema educacional público. Essa organização no mundo do trabalho pode ser entendida também como uma forma de codificar os conhecimentos, separando o saber e o agir (Stroobants, 1997).

10 A semiformação (Hallbildung) apresenta-se como o processo de embrutecimento da subjetividade do indivíduo, que converteu a formação (Bildung) em ideologia pelo crescente processo de hegemonia da indústria cultural. Para tratamento desse tema, ver também: Theodor W. Adorno e Max Horkheimer, Dialética do esclarecimento: fragmentos filosóficos, Rio de Janeiro, Zahar, 1985. 
proposição, visto que ela "prescinde da situação da fala, do uso da linguagem e de seus contextos, das pretensões, das tomadas de posição e dos papéis dialogais dos falantes". O ato de fala é revelador de uma estrutura que é, ao mesmo tempo, proposicional e performativa, pois a intenção do agente se dá como uma ação linguística, manifestando, explicitamente, sua intenção ao ouvinte.

Pelo processo de análise da linguagem, o conceito de performance associa-se a um mundo de forças expressivas, que tem no reconhecimento do outro sujeito a possibilidade de submeter os discursos legitimados às diferentes compreensões e interesses humanos. Nesse sentido, Habermas vê a importância da reflexão estética para uma teoria crítica da sociedade, mesmo dentro de um quadro teórico que privilegia a autorreflexão racional, efetuada na execução do agir comunicativo. A ação performativa sempre se retoma no presente do saber, assim como "a potência criadora de sentido, que hoje em dia se retirou em grande parte para os âmbitos do estético, conserva a contingência das forças verdadeiramente inovadoras" (Habermas, 1990b, p. 446).

Diante disso, podemos apontar caminhos para a questão da performance do professor, considerando a incompletude do projeto moderno e a necessidade de alargamento do conceito de performance para além da significação vigente. Então, partimos da necessidade dos cursos de formação de professores estarem voltados à formação obtida discursivamente, para não deixá-los presos a uma concepção meramente instrumental, que cria o estigma do professor paralisado em formulações abstratas e isento de expressão vital. Afinal, como Habermas (1990b, p. 172) assevera, o conceito de razão transforma-se em proferimentos dos quais podemos reivindicar racionalidade, surgindo a necessidade de dar conta da totalidade, que inclui uma razão situada como algo "concretizado na história, sociedade, corpo e linguagem".

A saída que o autor sugere, em sua teoria da ação comunicativa, está na perspectiva de recuperar as dimensões perdidas no ato educativo e correlacioná-las. Não se trata de superar a razão instrumental mediante uma racionalidade estético-expressiva, mas de explorar melhor essa dimensão na educação, analisando mais detidamente o significado da pretensão de veracidade que implica na dimensão estético-expressiva. Nessas condições, a estética está relacionada à percepção sensível (aisthesis) e à dimensão da originalidade do sujeito, criando um estado singular, em que algo pode relacionar-se consigo mesmo e produzir um sentido, quebrando a lógica habitual.

Pelo exposto até aqui, a ideia está em potencializar a instância da linguagem como instrumento privilegiado à performance do professor e fazer uma crítica reconstrutiva às tradições da prática educativa, para que o professor não sacrifique sua particularidade pelo excesso de formalismo, mas oriente-se por critérios capazes de assegurar a autenticidade expressiva e a razão ${ }^{11}$ autocrítica.

11 A razão para Habermas manifesta-se historicamente de forma linguística encarnada nos complexos de ação comunicativa e nas estruturas do mundo da vida. A teoria da ação comunicativa trata de uma ação que é linguisticamente mediada (interação 


\section{PERFORMANCE - O PONTO DE ENCONTRO DA RAZÃO COM A SENSIBILIDADE}

Evidentemente, não existe mundo totalmente independente da linguagem, visto que esta é o espaço de expressividade do mundo e a instância de articulação dos processos formativos humanos. A estética sempre se interpôs ao rígido racionalismo, e isso já nos é conhecido desde o século XVIII, quando Kant (1995) afirmou que conceitos sem intuições são vazios, ou seja, é inócuo um conhecimento sem uma contrapartida sensível (resultados científicos incompreensíveis). $\mathrm{O}$ aparato perceptivo, relativo à apreensão do mundo, adquire diferentes contornos nas formulações clássicas de Kant (1724-1804), cujas pretensões apontam para uma atividade reflexiva (articulada a processos intramundanos de aprendizagem) fundamentada numa tensão iniciada no livre jogo entre imaginação e razão, que tem a capacidade de humanizar. ${ }^{12}$

Kant vê a necessidade de proceder à análise crítica da própria razão como meio de estabelecer os limites e possibilidades para o conhecimento humano, pela sensibilidade e pelo entendimento. Nas palavras de Kant (idem, p. 142),

a aptidão do homem para comunicar seus pensamentos requer também uma relação entre a faculdade da imaginação e o entendimento para remeter intuições a conceitos e por sua vez conceitos a intuições, que confluem em um conhecimento.

No projeto kantiano, o conceito de imaginação, que está ligado ao entendimento do sujeito, é vital para o abandono do racionalismo e de suas repercussões dogmáticas, especialmente, no relacionamento da intuição sensível com o esquematismo. ${ }^{13}$ Ao empreender uma das muitas tentativas de divisão das belas-artes, ${ }^{14}$ Kant (idem, p. 165-166) parte da expressão estética, segundo a disposição de uma linguagem, e vê a arte

linguística) e disso decorre a reivindicação da dimensão pragmática da linguagem, que se refere ao uso reflexivo da ação humana comunicativa.

12 Para Kant (1995, p. 199-200), a propedêutica de toda arte bela encontra-se nos conhecimentos prévios que se chamam humaniora, presumivelmente, porque humanidade "significa de um lado o universal sentimento de participação e, de outro, a faculdade de poder comunicar-se íntima e universalmente". O filósofo elaborou três conceitos ainda hoje referenciais para a discussão sobre a arte, colocando o estético a serviço de fins próprios à ação e expressão humanas. Primeiramente, na formulação do belo como juízo reflexivo, e não como mero reflexo ou imitação da natureza; na noção de que existe uma relação entre juízo estético e sujeito, entendido aqui como sujeito de natureza subjetiva; e na ideia de que o juízo estético, assim como o juízo teleológico (com finalidade orgânica e objetiva), tem uma finalidade moral, que é o agrado desinteressado.

13 O esquematismo é o único mecanismo por meio do qual pode haver a aplicação das categorias (conceitos) às intuições sensíveis, ou seja, refere a multiplicidade sensível aos conceitos fundamentais que geram conhecimento. Tal conceito depende de um desempenho reflexivo dos sujeitos para sua realização, ou seja, ultrapassa a mera subjetividade em favor do discurso intersubjetivo.

14 Segundo Kant (1995), há somente três espécies de belas-artes que seriam uma arte livre: as elocutivas (são a eloquência e a poesia), as figurativas (da expressão por ideias 
como o modo de expressão de que os homens se servem no falar para comunicarem-se entre si tão perfeitamente quanto possível, isto é, não simplesmente segundo conceitos, mas também segundo suas sensações. Este modo de expressão consiste na palavra, no gesto, e no som (articulação, gesticulação e modulação). Somente a ligação destes três modos de expressão constitui a comunicação completa do falante. Pois pensamento, intuição e sensação são assim simultâneos e unificadamente transmitidos aos outros.

O que Kant mobiliza é que nosso saber tem compreensões estéticas de espaço comum ao ser humano e que, portanto, negar essa realidade sensível, que situa um juízo de gosto no plano da fala cotidiana, seria negar a própria comunicação e sua sociabilidade. A capacidade de julgar do ser humano (professor) não é formada nem por paradigmas, nem por regras, mas pelo fato de estarmos diante do outro e em comunicação com o mundo. Tomando por base os esforços teóricos de Kant, torna-se possível pensar a performance como um modo de sensibilidade para a vida, visto que o desenvolvimento dos sentimentos pode auxiliar na consideração das questões morais e na harmonia entre sensibilidade e racionalidade.

A maneira de ver a arte em Kant não termina no gozo estético, mas na comunicação de seu entusiasmo ao outro e ao mundo que habita, em intercâmbio comunicativo, que é a melhor forma de o homem entrar em contato consigo mesmo. ${ }^{15}$ Nessa perspectiva, o juízo estético é entendido e compartilhado intersubjetivamente, pois é uma formação de cultivo histórico de ampla significação para a cultura, em favor de um projeto pedagógico e político. Para Kant, a razão comunicativa não é destituída de corpo, como se fosse a espontaneidade de uma subjetividade constitutiva do mundo (em si mesma) e alheia ao mundo. Ora, isso ocorre pelo fato de que:

Kant, como é sabido, une ao conceito de conhecimento as realizações sintéticas da faculdade produtiva da imaginação e do intelecto, através da qual a variedade das sensações e das representações é organizada na unidade de experiências do juízo. A apreensão na contemplação, a reprodução na imaginação e a recognição no conceito constituem ações espontâneas, que atravessam aquilo que é múltiplo, recolhendo seus elementos e unindo-os numa unidade. (Habermas, 1990a, p. 160)

Diante dessas considerações, Habermas defende que não é possível abdicar o universalismo da tradição kantiana, pois no próprio conceito de racionalidade

estéticas e na intuição dos sentidos) e a arte do jogo das sensações (enquanto impressões externas dos sentidos, das sensações da audição e da visão).

15 Aqui, Kant (1995) alerta-nos para a questão de que uma língua não deveria constituir-se somente pelo uso, mas também pela razão, no sentido de pensar por si e jamais passivamente. Nesse entendimento, uma língua desprovida de razão cede à heteronomia, isto é, ao preconceito, derivando juízos falsos. 
comunicativa manifesta-se o consenso como uma forma de garantir a unidade percebida na multiplicidade de vozes, abrindo espaço à contingência e à pluralidade.

Como vimos, na ação comunicativa, o estético opera, em Habermas (1987), como um modo de racionalidade entre as esferas da sensibilidade e da razão, harmonizando-as (e nisso se assemelha a Kant). O filósofo admite que, embora os juízos estéticos possam ser racionalmente justificados, não teríamos o direito de erguer para eles uma pretensão de validade universal análoga à dos juízos teóricos e morais, visto que essas formas de argumentação se interpenetram e têm pretensões de validade próprias. Habermas retoma a pragmática kantiana, em que os sujeitos aprendem nas suas relações morais e cognitivas com o mundo, atentando para os limites da verdade consensual alcançada no nível do discurso. Segundo Habermas, Kant, com sua noção de autonomia, já introduz um conceito que só se pode explicitar plenamente dentro de uma estrutura intersubjetiva (performativa). E como essa ideia está ligada ao conceito de razão prática constituída pelo conceito de pessoalidade, só podemos preservar a filosofia kantiana dentro de uma estrutura que desenvolva a concepção de subjetividade em relações internas com a intersubjetividade (Habermas, 2004).

Nessa ótica, a concepção expressivista da estética perpassa a base comunicativa do saber, que reconstrói as condições universais do entendimento possível, independentemente dos pressupostos transcendentais do conhecimento. Como lembra Habermas (1987, p. 436, tradução minha), com proferimentos expressivos, "o falante se refere a algo no seu mundo subjetivo, e a rigor de uma maneira que ele gostaria de revelar diante de um público uma vivência à qual ele tem um acesso privilegiado". Esse debate converge na direção de que com a performance

se introduz uma atitude realizativa (performative Einstellung) de tipo global, para dar conta de que com cada ato de fala os participantes da comunicação se referem simultaneamente a algo no mundo objetivo, no mundo social e no mundo subjetivo. (idem, p. 422, grifos do autor, tradução minha)

A ação performativa é uma forma de racionalidade mais globalizante, porque proporciona um desdobramento realizador da própria comunicação intersubjetiva. Daí que o conceito de validez de uma oração não pode explicar-se com independência do conceito de desempenho (Einlösung), visto que necessita de condições contextualizadas, não padronizadas e contingentes dos processos de entendimento, o que implica ser criticada, corrigida e reconhecida intersubjetivamente por meio de boas razões. Mediante a atitude pragmática de linguagem, podemos assegurar uma ideia de entendimento das ações sociais materializadas nas diversas formas de saber, ${ }^{16}$ capaz de esclarecer as confusões geradas pelas patologias da comunicação e fazer emergir uma compreensão descentrada do mundo. Nessa versão,

16 A orientação habermasiana (1987, p. 426-427) de ação comunicativa oferece uma vantagem em relação ao saber racionalizado e institucionalizado, porque penetra 
em meio ao terrível reino das forças e ao sagrado reino das leis, o impulso estético ergue imperceptivelmente um terceiro reino, alegre, de jogo e aparência, em que desprende o homem de todas as amarras das circunstâncias, libertando-o de toda a coerção moral ou física. (Habermas, 1990b, p. 68-69)

Por essa via, a performance discursiva a que se refere Habermas revela no impulso estético o ato de criação e atualização do sujeito como arte de educar em tempo presente, relacionada a uma discussão responsável, mediada racionalmente conforme os recursos do mundo da vida, que garantem valor reflexivo às ações linguísticas.

Nessas condições, o desempenho comunicativo surge como uma faculdade do juízo inter-racional de comparação e relativização e como uma instância capaz de realizar as mediações e as transições necessárias à busca de soluções adequadas para problemas teóricos, práticos e estéticos do cotidiano. Segundo Habermas (idem), a ação comunicativa implica adotar uma atitude performativa em que os atores participantes (falantes e ouvintes) buscam com sua ação satisfazer condições de entendimento e solidariedade. Com essa posição, o autor acentua o enfoque performativo e critica os excessos objetivantes e intencionalistas da teoria dos atos de fala de Austin e Searle, na medida em que apresentam ligações ainda que remotas do paradigma da representação. As pretensões de validade inscritas na dimensão performativa permitem que a prática intramundana se ligue a processos de aprendizagem que oportunizam uma contínua modificação das estruturas de mundo.

Partindo de uma teoria pragmática como forma de atividade social, Habermas (1987) tematiza a ação dramatúrgica, a qual serve à autoexpressão e abrange as dimensões constitutivas da racionalidade estético-expressiva. Vale especificar melhor a ação dramatúrgica como parte constitutiva da ação expressiva do professor que, "ao deixar transpassar algo de sua subjetividade, o ator busca ser visto e aceito pelo público de uma determinada maneira" (idem, p. 131, tradução minha). Certamente, o professor, ao realizar sua ação pedagógica, coloca com maior ou menor intensidade seus valores emocionais e pessoais, bem como sua intencionalidade para acolher as demandas do mundo vivido. A força problematizadora das experiências estéticas com o mundo pode ser capaz de abrir os olhos, de provocar novas maneiras de ver, novos enfoques e novos modos de comportamento (Habermas, 1990a). Nesse contexto, é bom notar que:

As experiências estéticas não estão embutidas em formas da prática; elas não estão referidas a habilidades cognitivo-instrumentais e a representações morais,

os processos cooperativos de interpretação e se integra no saber contingente e contextualizador do mundo da vida. A sociedade precisa conectar-se com um conceito de mundo da vida complementar ao de ação comunicativa, para que possamos problematizar a objetividade e padronização dos distintos saberes, entendendo a linguagem como princípio de socialização e reflexão, mediante um saber holisticamente estruturado que sacode nossas certezas de sentido do mundo. 
que se formam no interior de processos intramundanos de aprendizagem; elas estão entrelaçadas com a função da linguagem que constitui e que explora o mundo. (idem, p. 94)

A posição habermasiana dirige-se à consideração do processo de aprendizado estético não em referência ao progresso de conteúdos de obras artísticas, mas à constituição de uma atitude hipotética e problematizadora, a qual caracteriza a experiência de uma subjetividade libertada da força da tradição e dos imperativos sociais.

Para o filósofo, tanto a radicalização da experiência estética quanto a subjetividade libertada são consequências do mesmo processo de destranscendentalização, ${ }^{17}$ visto que a dimensão estético-expressiva intensifica a unidade no múltiplo. É importante assinalar que o trabalho do professor é uma ação social, principalmente pela perspectiva de sujeitos agentes que se justificam no uso da linguagem pública como expressão da sua vida profissional em ato, similitude revelada nas decisões e interpretações dos atores dentro de seu mundo da vida. De acordo com isso, podemos dizer que o ato expressivo estabelece uma relação ampliadora do saber, pois o professor comunica algo desse mundo, como uma retomada criadora de si mesmo.

\section{A TíTULO DE CONCLUSÃO: PERFORMANCE E EDUCAÇÃO}

Falar da performance hoje é trazer à tona as possibilidades estéticas do agir humano, pois "afeta aquilo que é conhecido; ela modifica o conhecimento" (Zumthor, 2007, p. 32). Isso porque a performance em sua existência discursiva é um elemento indispensável à sociabilidade humana, visto que incorpora os diferentes papéis da comunicação para desenvolver um novo campo de atuação e expressão, no qual o mundo e os processos de aprendizado se concretizam. Por tudo isso, a performance implica a abertura para as questões da atualidade, numa prática permeada de contexto histórico-cultural em que o sujeito assume sua responsabilidade e o seu papel social por meio de um desempenho que promova a pluralidade de significados.

Nesse sentido, a performance sugere a ação complexa e movente que permite a recriação de um saber, questionado incessantemente. Nas palavras de Paul Zumthor (2005, p. 87),

a performance é uma realização poética plena: as palavras nela são tomadas num conjunto gestual, sonoro, circunstancial tão coerente (em princípio) que, mesmo distinguindo mal as palavras e frases, esse conjunto como tal faz sentido.

17 Com referência à destranscendentalização, sobretudo as ideias de razão teóricas se colocam igualmente fora do mundo estático dos inteligíveis e ostentam sua dinâmica no interior do mundo da vida. Do mundo inteligível temos apenas uma ideia, diz Kant, nenhum conhecimento (Habermas, 2002, p. 45). Para a destranscendentalização da razão, Habermas sugere a libertação do potencial comunicativo reprimido, tendo como pano de fundo o mundo prático pré-reflexivo. 
Desse ponto de vista, a performance imprime nas palavras a máxima expressividade, porque é um modo vivo de comunicação poética, é relativo às condições de expressão, da percepção e designa um ato de comunicação enquanto tal.

Levando adiante esse debate, é possível afirmar que a experiência expressiva surge como possibilidade de compreender as novas exigências trazidas pela pluralidade do saber, transcendendo as fronteiras unilaterais e ampliando, de certa forma, o conceito de formação. Mais ainda, de acordo com Zumthor (2007, p. 67), "a performance é ato de presença no mundo e em si mesma", ato no qual o mundo se concretiza. Ao despertar a racionalidade pedagógica para a dimensão linguístico-expressiva, buscamos extrair das contradições o potencial do discurso performativo capaz de evidenciar as diferenças e partilhá-las intersubjetivamente, mostrando que a dimensão estética não está isolada do cotidiano e alheia à formação de identidades pessoais e coletivas.

A partir daí, a experiência formativa do educador, compartilhando o diagnóstico de Walter Benjamin (1989), acontece no núcleo da própria formação compreendida como estrutura da percepção do conhecimento e consciência estética do vivido. Segundo o filósofo, a experiência do sujeito parte do saber da tradição cultural em conjugação com a experiência presente, o que a torna fonte inesgotável e originária de acontecimento, sob a forma de ação e pensamento sensível do sujeito no processo coletivo.

Para aprofundar o entendimento sobre a performance do professor, as discussões de Freire (2001) apresentam perspectivas para repensar a atuação desse profissional, condizentes com o espírito crítico de nossos tempos, apostando nessa prática dialógica, política e pedagógica da formação. Segundo Freire (idem, p. 55), "a educação será tão mais plena quanto mais esteja sendo um ato de conhecimento, um ato político, um compromisso ético e uma experiência estética”. Daí que toda justificação pedagógica é perpassada por momentos estéticos, constituindo-se num ato de arte que privilegia a performance e a restauração da intersubjetividade da comunicação.

A sensibilidade com que Freire problematiza a dimensão social da formação do professor aponta para a dimensão estética de sua prática que, sem abrir mão da utopia, da seriedade e da simplicidade inerente ao saber da competência, pode ser movida pelo desejo e vivida com alegria. Na obra Sobre educação, que escreveu em coautoria com Sérgio Guimarães, Freire (1984,p. 63-64) constata que a performance do professor se dá por meio da entonação da palavra, do corpo, do gesto; e isso revela uma maneira de perceber o objeto discutido. Mas adverte que o professor parece querer esconder o próprio corpo por trás da profissão, como um corpo inconsciente no fazer sem atuar, sem pensar.

A importância do corpo é indiscutível; o corpo move-se, age, rememoriza a luta de sua libertação, o corpo afinal deseja, aponta, anuncia, protesta, se curva, se ergue, desenha e refaz o mundo. [...] Há muito sensualismo que o corpo guarda e explicita, ligado até mesmo à capacidade cognoscente. Acho um absurdo afas- 
tar o ato rigoroso de saber o mundo da capacidade apaixonada de saber. Eu me apaixono não só pelo mundo, mas pelo próprio processo curioso de conhecer o mundo. (Freire, 1995, p. 92)

Evidentemente, a ação performativa para Freire não resulta da cognição, mas se relaciona com a transmodelagem dos objetos, que envolve todos os sentidos do sujeito, forçando-o a lidar com as novas possibilidades geradas na experiência educativa, que ampliam as relações com o mundo. Ao dizer uma proposição, o professor não se utiliza apenas da fala, as expressões gestuais e corpóreas enriquecem ou completam seu sentido e, por isso, num diálogo, os interlocutores envolvem-se performaticamente para interpretar a mensagem.

Parafraseando Freire e Habermas, podemos dizer que o entendimento linguístico, na problematização de diferentes interpretações de mundo, se compõe de mecanismos de coordenação das ações que visam ao estabelecimento de relações interpessoais. Fora da coordenação das ações (âmbito da interação), é impossível pensar o processo, o aprender a aprender para realizar performances próprias, o estabelecimento de uma rede comum de sentidos, informados e produzidos, passíveis de transmissão na experiência pedagógica. A mudança operada quer reconstruir o sentido da racionalidade comunicativa na dimensão performativa como um conceito não reduzido de razão, mas elemento mediador do entendimento e da integração social (Habermas, 1989, p. 507).

Concluímos daí que a ideia de provisoriedade, de decepções performativamente vivenciadas e múltiplas racionalidades estimulam a curiosidade e a abertura da educação à sensibilidade, para o desconhecido e o inusitado. Habermas (2009, p. 20) afirma que "[...] a solução construtiva dos problemas provocados por uma perturbação das práticas habitualizadas conduz a convicções modificadas, que por sua vez são e precisam ser postas à prova”. Por tudo isso, na história da educação, o ato de educar foi considerado uma arte por essa dimensão de originalidade nas relações humanas que lhe é inerente e que ultrapassa o instituído, os planos e avaliações. Enfim, conforme Habermas (idem, p. 23-24),

só podemos aprender alguma coisa com a resistência, performativamente vivenciada, da realidade na medida em que tematizamos as convicções implicitamente postas em questão e aprendemos com as objeções de outros interlocutores.

Habermas indica que num jogo de regras intersubjetivamente vigentes, a performance emerge das manifestações linguisticamente simbolizadas, das representadas em ações e das manifestações expressivas ligadas ao corpo. Sem abandonar a sensibilidade e a imaginação, o educador pode assumi-las como instrumento de realização e entendimento do mundo e parte da indeterminação de sua atividade, como limites a serem transpostos.

Enquanto as práticas formativas permanecerem impondo uma racionalidade fragmentada das formas de ver e entender o mundo com finalidade estritamente 
didática e técnica, continuará existindo um distanciamento que não permite aos sujeitos suas múltiplas expressões. A determinação da linguagem proveniente de sua função designativa e transmissiva de conhecimento não é falsa, mas pedagogicamente insuficiente, pois inviabiliza processos de comunicação vinculados a qualquer pluralidade de sentido do mundo.

Tal constatação revela que a performance educativa, enquanto um saber subjacente ao atuar, à conversação, ao viver, ao criar inventivo, configura-se como uma dimensão perdida em nosso tempo, porque destituída das condições de sua própria realização, de sua intensidade linguístico-expressiva de sentido coletivo. Falar na educação contemporânea significa atuar, materializando voz, gestos, movimento, tornando viva e dinamizando a própria possibilidade da educação enquanto processo expressivo de não só sofrer o mundo, mas agir nele, revelá-lo nas suas virtualidades e transformá-lo. A dimensão estética é precisamente o território no qual a função linguística de abertura do mundo legisla, no empenho pela emancipação, podendo ser analisada como um processo formativo e educativo.

A ação do professor no mundo se apresenta como uma das necessidades atuais de entendimento e de problematização, porque implica necessariamente atos de fala performativos, constituindo o horizonte estético (em que o agir perde sua trivialidade e sua solidez inquestionada), que remete à complexidade do mundo da vida. Embora o conceito de performance apresente a expressão mais radical de uma práxis enquanto realização humana (Habermas e Zumthor), na formação de professores prevalece uma perspectiva de performance institucionalizada segundo uma racionalidade técnica da produtividade (visão representacionista e monológica da linguagem).

O debate sobre a performance favorece a revisão de conceitos, equilibrando, no sentido aristotélico, a relação entre os mundos inteligível e sensível, para enfrentar as contingências do processo educativo em busca da constante autocriação à melhoria do agir docente. Certamente, os riscos do abandono da dimensão linguístico-expressiva da performance na estruturação da educação apresentam problemas como a fragmentação de conhecimentos e a formação de sujeitos opacos, indiferentes ao outro e empobrecidos da vida cultural. Sob esse aspecto, uma das funções da educação que preza pela formação (Bildung) é precisamente a de nos sensibilizar para esse saber prático-expressivo, que só pode ser pensado por uma ação pedagógica que tenha pretensões de combater a trivialidade da performance produção em busca da própria sensibilidade na relação com a alteridade.

\section{REFERÊNCIAS}

Aristóteles. Rhétorique. Paris: Belles Lettres, 1932.

. Poétique. Tradução Joseph Hardy. Paris: Belles Lettres, 1995.

Austin, John Langshaw. Quando dizer é fazer. Porto Alegre: Artes Médicas, 1990. 
Benjamin, Walter. Charles Baudelaire: um lírico no auge do capitalismo. Tradução José Martins Barbosa e Hemerson Alves Batista. São Paulo: Brasiliense, 1989. (Obras escolhidas, v. 3).

Chauí, Marilena. Convite à filosofia. 12. ed. São Paulo: Editora Ática, 1999.

Freire, Paulo. A educação na cidade. 2. ed. São Paulo: Cortez, 1995.

. Política e educação: ensaios. 5. ed. São Paulo: Cortez, 2001.

2002.

.Professora sim, tia não: cartas a quem ousa ensinar.11. ed. São Paulo: Olho d’Água,

.; Guimarães, Sérgio. Sobre educação: diálogos. 3. ed. Rio de Janeiro: Paz e Terra, 1984. v. II.

Gadamer, Hans-Georg. A razão na época da ciência. Rio de Janeiro: Tempo Brasileiro, 1983.

Verdade e método. 4. ed. Tradução Flávio Paulo Meurer. Petrópolis: Vozes, 2002.

Habermas, Jürgen. Teoría de la acción comunicativa I: racionalidad de la acción y racionalización social. Madrid: Taurus, 1987.

. Consciência moral e agir comunicativo. Rio de Janeiro: Tempo Brasileiro, 1989.

.Pensamento pós-metafísico: estudos filosóficos. Tradução Flávio Beno Siebeneichler.

Rio de Janeiro: Tempo Brasileiro,1990a.

. O discurso filosófico da modernidade. Lisboa: Dom Quixote, 1990b.

. La lógica de las ciências sociales. 3. ed. Madrid: Tecnos, 1996.

. Teoría de la acción comunicativa II: crítica de la razón funcionalista. Madrid:

Taurus, 1999.

. A ética da discussão e a questão da verdade. Tradução Marcelo Brandão Cippola. São Paulo: Martins Fontes, 2004.

. Agir comunicativo e razão destranscendentalizada. Tradução Lucia Aragão. Rio de Janeiro: Tempo Brasileiro, 2002.

. Verdade e justificação - ensaios filosóficos. 2. ed. Tradução Milton Camargo Mota. São Paulo: Edições Loyola, 2009.

Hermann, Nadja. Validade em educação: instituições e problemas na recepção de Habermas. Porto Alegre: EDIPUCRS, 1999.

Ética e estética: a relação quase esquecida. Porto Alegre: EDIPUCRS, 2005.

Kant, Immanuel. Crítica da faculdade do juizo. 2. ed. Tradução Valério Rohden e Antônio Marques. Rio de Janeiro: Forense Universitária, 1995.

Marx, Karl. Manuscritos econômico-filosóficos. In: MARX. Os pensadores. São Paulo: Abril Cultural, 1978. p. 9-198. (Os pensadores).

Merleau-Ponty, Maurice. Fenomenologia da percep̧çao. São Paulo: Martins Fontes, 1971.

Stroobants, Marcelle. A visibilidade das competências. In: Ropé, Françoise; TanguY, Lucie (Orgs.). Saberes e competências: o uso de tais noções na escola e na empresa. 2. ed. Campinas: Papirus, 1997. p. 135-166. 
Zumthor, Paul. Escritura e nomadismo: entrevistas e ensaios. Tradução Jerusa Pires Ferreira e Sonia Queiroz. Cotia: Ateliê Editorial, 2005.

. Performance, recep̧cão e leitura. Tradução Jerusa Pires Ferreira e Suely Fenerich. São Paulo: Cosac Naify, 2007.

\section{SOBRE A AUTORA}

Elaine Conte é doutoranda em educação pela Universidade Federal do Rio Grande do Sul (UFRGS).

E-mail: elaineconte.poa@gmail.com

Recebido em abril de 2011

Aprovado em março de 2012 


\section{ELAINE CONTE}

\section{Aporias da performance na educação}

O ensaio analisa a questão da performance na educação pela perspectiva filosófica da ação comunicativa, que acrescenta importantes elementos para o entendimento da performance como dimensão pragmática, estética e expressiva do agir humano. Pelo caminho de inspiração hermenêutica, repensamos os horizontes da performance sob a lógica moderna da produção (por coerção, tecnicamente além do agente) e sob uma racionalidade comunicativa que responde às necessidades de realização humana. A performatividade da linguagem exibe um potencial de inovação radical e uma indefinição que rompe com a convencionalidade e as restrições formais das práticas educativas, colocando em jogo as instâncias do inteligível e do sensível. Considerando que nas obras de Habermas não fica explícita uma teoria da performance, o tema é desenvolvido no diálogo com outros pensadores, como momento que requer um avanço na crítica ao performativo da linguagem para aprender a realizar performances próprias.

Palavras-chave: performance; educação; dimensão estético-expressiva.

\section{Performance aporias in education}

This study examines the issue of performance in education from the philosophical perspective of communicative action, which adds important elements for understanding performance as a pragmatic, aesthetic and expressive dimension of human action. With hermeneutic inspiration, we have rethought the horizons of performance under the modern logic of production (through coercion, technically beyond the agent) and under a communicative rationality that meets the needs of human fulfillment. Language performativity shows a potential for radical innovation and a lack of definition that breaks the conventionality and the formal constraints of educational practices, bringing into play the dimensions of intelligibility and sensitiveness. Considering that a performance theory is not explicit in Habermas' works, the theme is developed in dialogue with other thinkers, as a moment that requires an advance in the criticism of the performative dimension of language to learn to make one's own performances.

Keywords: performance; education; aesthetic-expressive dimension.

\section{Aporías de lo desempeño en la educación}

El ensayo analiza la cuestión del desempeño en la educación, según la perspectiva filosófica de la acción comunicativa, que añade importantes elementos para la comprensión del desempeño tal como la dimensión pragmática, estética y expresiva de la acción humana. Desde la inspiración hermenéutica, repensamos los horizontes del desempeño en la lógica moderna de la producción (mediante coacción, técnicamente más allá del agente) y de una racionalidad comunicativa que responde a las necesidades de realización humana. La performatividad del lenguaje exbibe un potencial para la innovación radical y una incertidumbre que rompe con los convencionalismos y las limitaciones formales de la práctica educativa, la puesta en juego entre las instancias de lo inteligible y de lo sensible. Teniéndose en cuenta que en las 
obras de Habermas no queda explícita una teoría del desempeño, el tema se desarrolla en el diálogo con otros pensadores, como un momento que requiere un avance fundamental en la critica del lenguaje performativo para aprender a llevar a cabo sus propias actuaciones.

Palabras clave: desempeño; educación; dimensión estético-expresiva. 